\title{
Strategic Highway Research Program
}

\author{
Damian J. Kulash \\ Executive Director \\ National Research Council \\ Strategic Highway Research Program \\ Washington, D.C.
}

The biggest problems our roads face are not corrosion by salt, not wear by heavy trucks, not cracking during sub-zero weather, nor rutting in intense heat. The biggest problem they face is indifference-indifference about roads, indifference about the people who manage them, and indifference about the new ideas going into roads.

Indifference led the United States, just a few years back, to a road system that was deteriorating. Indifference was reflected in declining investment in roads. During the seventies, state disbursements for roads in the United States (in constant dollars) dropped from $\$ 48$ billion to $\$ 29$ billion, even as record volumes of people and goods moved on these roads. Indifference lulled us into cutting our investment in road research in half: it fell (in constant dollars) from $\$ 110$ million in 1972 to $\$ 55$ million a decade later. This indifference was reflected in the declining percentage of engineering students that chose civil engineering majors: 20 percent in 1976; 13 percent in 1984. In short, the late seventies and early eighties brought an erosion in our roads, in new ideas, and in the recruitment of people that are essential to a dynamic industry.

Then we woke up. In 1982, the public, the United States Congress, and the mass media suddenly awakened to the immense importance of our highway transportation system. U.S. expenditures for highway transportation-private and public - are twice as large as U.S. expenditures for defense. One-sixth of the gross national product of the United States goes into the highway transportation system. More than 90 percent of U.S. industrial output moves over the road system. Our roads are our economic backbone. We could not afford to be indifferent about them. New attention was directed to the money, the innovation, and the people involved with our highway system.

Five years ago the U.S. Congress passed the Surface Transportation Assistance Act of 1982, which increased the motor fuel tax by five cents per gallon and pumped $\$ 5.4$ billion more per year into federal highway and transit programs. Since then, 35 states have also increased their highway user fees. This new infusion of resources over the last four years has started to bring new life to the industry. Materials suppliers, 
contractors, public officials, and engineering students have started paying more attention. We've started to turn the corner from indifference toward new ideas, new talent, and better financing.

This comeback brings more than money: It also brings a new push for innovation in the highway industry. About five years ago, many of the nation's highway leaders were concerned about innovation. Top officials in state highway agencies were frustrated by costly, often unexplained failures. They were frustrated when their research staff couldn't find solutions to failures problems. At the same time, highway research programs and institutions were stretched dangerously thin. In 1982, the U.S. was spending about one-fifth of one percent of its highwayconstruction resources on research. That is neglect, by any measure. High tech industries, like computers and aerospace, spend 10 to 50 times more on reseach than we do, when research expenditures are compared as a proportion of gross sales. Even low-tech industries like mining, steel, and paper spend about eight times more of their gross sales revenue on research than we do. Further, the scarce available research dollars are spread far and wide. Many of the urgent problems they attack are specific to a particular climate, type of material, or other local feature. (This is an essential reseach activity the highway community does well. But it's not the only path to innovation.) The available resources are also scattered throughout 50 states, several federal agencies, various private companies, and elsewhere. Typically, highway research is packaged in separate projects costing $\$ 100,000$ to $\$ 200,000$. This is generally adequate to identify what has been done on a specific problem, and to evaluate some possible new approaches. This institutional approach has served us well and must be continued. Each of the many agencies involved in highway construction confronts unique problems stemming from their designs, loadings, materials, or climates. Each needs a strong problemsolving capability to be productive and innovative.

What was lacking in this structure was the capability to attack fundamental problems that cut across, yet interact with, local conditions. No single agency had the money, or the responsibility, to solve some of these biggest, most costly, most widespread problems. This is where SHRP comes in. It does not replace the important problem-solving research that is now conducted by states, the Federal Highway Administration, universities, and others. It does fill a gap that these organizations can't address. SHRP focuses exclusively on four national problem areas. Each is an area where the nation spends billions of dollars each year, and where innovative approaches will yield big savings. These four research areas are also ones where numerous site-specific factors influence performance. Only a large, systematic, and consistent approach in these areas can produce results that have national significance. The four areas are: 


\section{Long Term Pavement Performance}

The U.S. spends $\$ 20$ billion per year on pavements, and more and more of this is going into replacement of existing pavements. Although we typically design pavements to last 20 years, our actual experience varies a lot. Some roads last 30 years. Some fail in two.

Much of our current pavement-design know-how came out of the AASHTO Road Test, conducted almost 30 years ago. This was a massive experiment, costing around $\$ 100$ million in today's dollars. Six test loops were built, each containing sections with different designs and materials. Each of the six test loops was subjected to a different axle loadings by running test vehicles of known weight. This experiment produced design equations that tied together the key design, materials, and traffic variables. They have been applied in hundreds of billions of dollars of pavement construction, both here and abroad. This experiment is counted among the biggest successes in the history of highway research, and justifiably so. But valuable as it is, it was inherently limited. It took place in one location-Ottawa, Illinois-and thus reflects only one set of climate and sub-grade soils. It was an accelerated test, and thus cannot reflect the effect of age, and its interaction with climate and traffic. It was a test to failure, and may not reflect accurately the effects of normal maintenance practices. Because of these inherent limitations, many continue to question whether the results of the AASHTO Road Test apply to their specific area or materials. The only way we are going to resolve these questions is through a broader road test. Such a test must include varied climates, sub-base soils, pavement ages, and maintenance treatments. This experiment, by its nature, would have to be located in several regions, and monitored for many years. SHRP plans to do exactly this, using about 2,000 pavement sections located throughout the United States and indeed throughout the world. These sections will be selected carefully to span the full range of variables to be studied. Their traffic and condition will be monitored carefully and consistently. The resulting data will be analyzed to produce pavement design equations that can be applied with greater confidence in varied settings. Even if these new designs save us only a few percent, in terms of reduced construction costs, this will amount to savings of hundreds of millions of dollars a year. It is a difficult project to launch, to coordinate, and to maintain, but we can't afford not to do it.

\section{Asphalt Materials}

The United States has been building asphalt pavements for the past century, and we have developed extensive knowledge of how different asphaltic materials perform in specific mixtures and applications. Nevertheless, premature failures of asphalt pavements, even though they are not common, are costly and disruptive. Many of these failures occur 
because of errors in the mix design or during construction. Such errors can and should be reduced through better training and knowledge sharing, and these steps are being taken by different programs and organizations. But part of the problem is the inability of our product specifications to pin down all the key properties that affect performance. Different asphalts of the same grade behave differently. A large amount of knowledge and training is needed to work around these differences-too much, we think. We are asking more than we can reasonably expect from decentralized field staff dealing with varied materials and diverse situations.

SHRP's initial concentration is on the production of improved asphaltic materials - through more performance-oriented specifications and through development of improved asphaltic binders. This will result in greater uniformity among asphalts meeting identical specifications. It will yield a better understanding of asphalt's fundamental characteristics, and how these affect pavement performance. It will develop asphalt testing procedures that more closely predict pavement performance.

These are difficult steps to achieve, because public agencies, paving contractors, and material suppliers must all work together if they are to be successful. Thus far, we are pleased to say, the cooperation among these various industries and agencies has been excellent, and we look forward to seeing a working partnership between SHRP and industry as we push for innovation in this area.

\section{Concrete and Structures}

The Concrete and Structures Program comprises two subprograms: Bridge Component Protection, and Cement and Concrete. The main thrust of the bridge component program is to increase the durability of existing bridges by protecting them from corrosion, and removing corrosion where it does occur. Salt frequently penetrates concrete bridge decks and corrodes the embedded reinforcing steel. As the reinforcing steel corrodes, it expandes and causes spalling in the concrete. We now face some $\$ 20$ billion of needed rehabilitation due to this problem, and this figure is growing by $\$ 500$ million annually. SHRP is investigating novel and improved methods of testing structures where corrosion is suspected, and providing a range of repair and rehabilitation techniques that can be used to extend the life of deteriorating structures. The cement and concrete subprogram is searching for methods of improving the durability of concrete. Among the specific problem areas we are focusing on is alkali aggregate reaction, where the silicates present in some aggregate rocks react with the cement to absorb water, causing swelling that breaks up the concrete. SHRP will also investigate ways to minimize deterioration of existing concrete pavements due to freezing and thaw- 
ing. Results of this research may include better mix designs that are tolerant of a wider range of aggregates, and new non-destructive testing methods to check mix composition during the construction phase.

\section{Highway Operations}

Maintaining our highways, and keeping them free of snow and ice, requires constant attention. These are labor-intensive tasks. They are also tasks that are performed by field workers with little supervision, working in highly decentralized organizations. Workers often get the necessary know-how through their own experience, through their supervisor's rules of thumb, or through recommendations passed along by their co-workers.

There has been surprisingly little systematic testing and evaluation of the different products used in highway maintenance, whether they be patching materials, sealants, or surface dressings. Given the large size of this market, that's surprising. We need some form of consistent product and process evaluation to make highway maintenance more cost effective. Many of our current practices have evolved without systematic evaluation. What works for one agency may or may not work well for another because they have different amounts of staff expertise, have different product needs, use contractors for different functions, or have different procurement practices. Reliable, comparable evaluation of competing techniques or products is needed. SHRP will evaluate chip seals, slurry seals, and other surface dressings so that their cost and performance can be compared. Similarly, SHRP will evaluate materials and equipment for surface repairs.

The use of salt to de-ice highways has increased tenfold since the mid ' 50 s. This rapid rise in salt use has been accompanied by deterioration of bridges, pavements, and vehicles, and it creates environmental problems as well. Innovative ways to apply non-chemical energy at the ice-pavement interface could keep highways free of ice and snow, using less salt. Improved physical snow-removal techniques will help also. In addition, use of modern sensor and communications technologies can make our snow-removal operations more efficient. SHRP will be doing research in all of these areas. In some cases, SHRP will explore fundamental properties of the ice-pavement bond: how it can be prevented, and how it can be destroyed. It is too early to say exactly what may grow out of this research. Perhaps pavement surface additives that retard ice bonding. Perhaps additives to salt that will make it more effective, or less damaging. Perhaps devices that use laser or microwave radiation to prevent or break ice bonding. There are many potentially promising, innovative approaches. Not all of these technologies will prove economical and effective, and SHRP is structured to identify and develop the most promising possibilities.

These four areas-asphalt, pavement performance, concrete and 
structures, and highway operations - are where SHRP will be concentrating. This focus grew out of an overall review of highway researchthe Strategic Transportation Research Study which was published done by TRB in 1984 . This study drew together a blue ribbon committee of state highway leaders, academic leaders, and industry research executives. They pinpointed the four areas that I have just described. During the subsequent two years detailed research plans were developed in each of these areas. In 1986, these Research Plans were published by the National Cooperative Highway Research Program, and distributed widely. They continue to be the technical blueprint for SHRP.

The states, through the American Association of State Highway and Transportation Officials, signed an agreement with the Federal Highway Administration and the National Research Council to make SHRP a unit of the National Research Council. SHRP is headed by a 15 -member executive committee, which includes government, universities, industry, and other organizations. This committee is chaired by Thomas Larson, who recently completed an eight-year term as Secretary of Transportation in Pennsylvania.

Events have accelerated rapidly since April 1987, when the U.S. Congress approved $\$ 150$ million for the five-year SHRP program. With the program's funding secured, SHRP moved forward quickly and awarded its first quarterly round of contracts, totaling $\$ 16$ million, October 8 .

SHRP's FY 1988 program includes 29 contracts that cover all four technical areas of SHRP. Although FY 88 will be a start-up year of lessthan-average spending for SHRP, it is the biggest year for contracting. Most SHRP contracts will be multi-year agreements. Many of the contractors that join the SHRP team this year will be the same ones introducing innovative materials or services three or four years from now. Widespread use of multi-year contracts gives SHRP the potential to keep development on the fast track without interrupting progress; to pin down the details of next steps, and to put them out to competitive bid.

Meanwhile, the design of next steps can take place in parallel with ongoing research, and contractors on the team can continue uninterrupted if they are performing well and making progress. This offers substantially more continuity than conventional, step-at-time contracting, where research plans are detailed in advance and executed through a series of intermittent design and performance phases. By bringing this additional continuity to the research process, SHRP offers a greater prospect of security. We believe that this will stimulate contractors to make the investments in facilities, technical expertise, and management that are necessary for success. It will help to build lasting professional and institutional capability in various areas of highway technology that will endure beyond SHRP's brief life.

At the same time, the availability of contract funds in future years 
is not automatic or guaranteed. Instead, out-year funding depends upon a contractor's performance and progress. To the maximum extent possible, SHRP Program Announcements (Requests for Proposals) set out performance and progress criteria that establish the basis upon which funding decisions for future years will be made. Performance criteria may include the ability to stick to the proposed work plan, schedule, and budget, or to a mutually agreed-upon improvement to the proposed plan. They may include the contractor's responsiveness and flexibility in modifying plans to incorporate improvements requested by SHRP, reflecting insights gleaned through SHRP's Executive Committee or Advisory Committees. A contractor's progress toward the development of usable innovation also depends on good fortune. Some of SHRP's technical areas will prove to be ones of rapid advancement. Other areas will prove to be stubbornly resistant to new insights.

SHRP's Executive Committee, which has the responsibility to keep the research program on the productive track, must periodically evaluate the activities and accomplishments of the research team. It must decide which activities to continue, which to modify, and which to curtail. Careful use of these controls is essential to keep SHRP targeted on areas with the greatest practical payoffs. This will take hard-nosed management by the SHRP Executive Committee, by the SHRP staff, and by the research contractors themselves. It involves balancing the bottom-up view of where technological change is feasible with the top-down view of where this change is worthwhile. New technologies may require new specifications or standards, new designs, new training, new contracting approaches, new procurement processes, or new staff capabilities. The exceptional potential of some new technologies will warrant these difficult changes. Other technologies will need to be refined until their demands upon users become more manageable. These will be tough decisions. To make them wisely, SHRP will continue to rely on active participation of management leaders and technical experts throughout the world's highway community. 